\title{
Quiz: Imaging
}

A solid pulmonary nodule in asymptomatic 54year-old male patient was detected on chest X-Ray during routine checkup. An ECG-triggered cardiac computed tomography (CT) images performed for the differential diagnosis of the nodule showed that the thought "solid pulmonary nodule" was actually an outward growth of the wall of the distal part of the aortic arch (Fig 1).

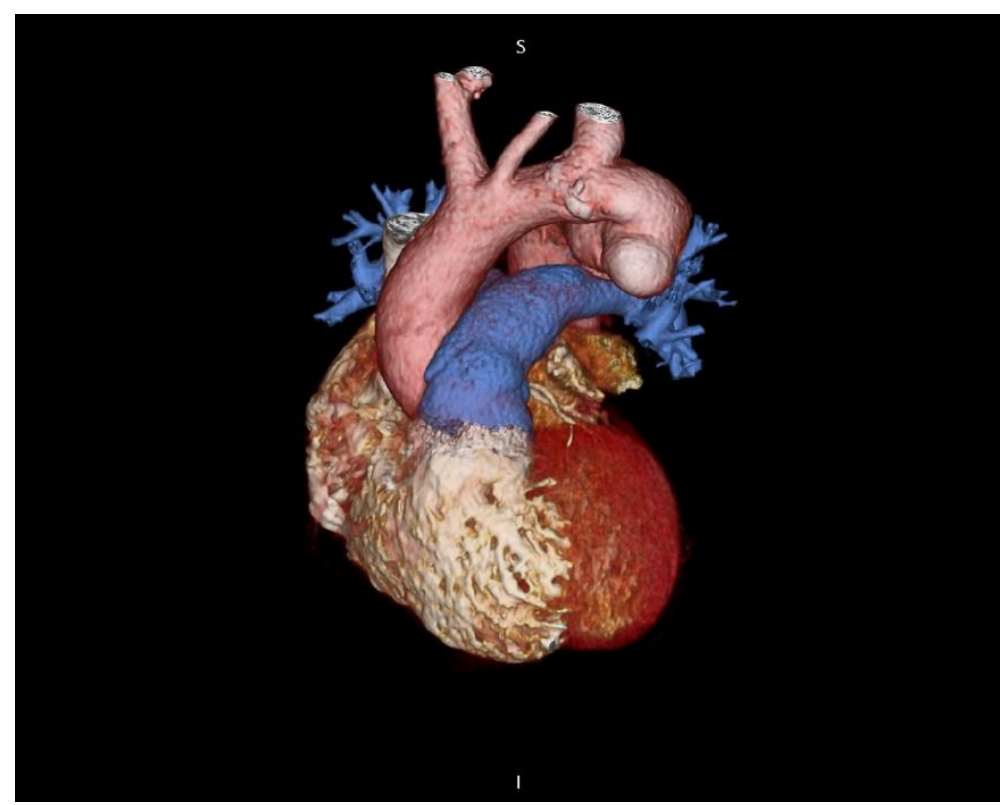

A)
What is your diagnosis?

A) Penetrating atherosclerotic ulcer in aortic arch

B) Double aortic arch

C) Aneurysm of the ductus arteriosus diverticulum

D) Kommerell's diverticulum

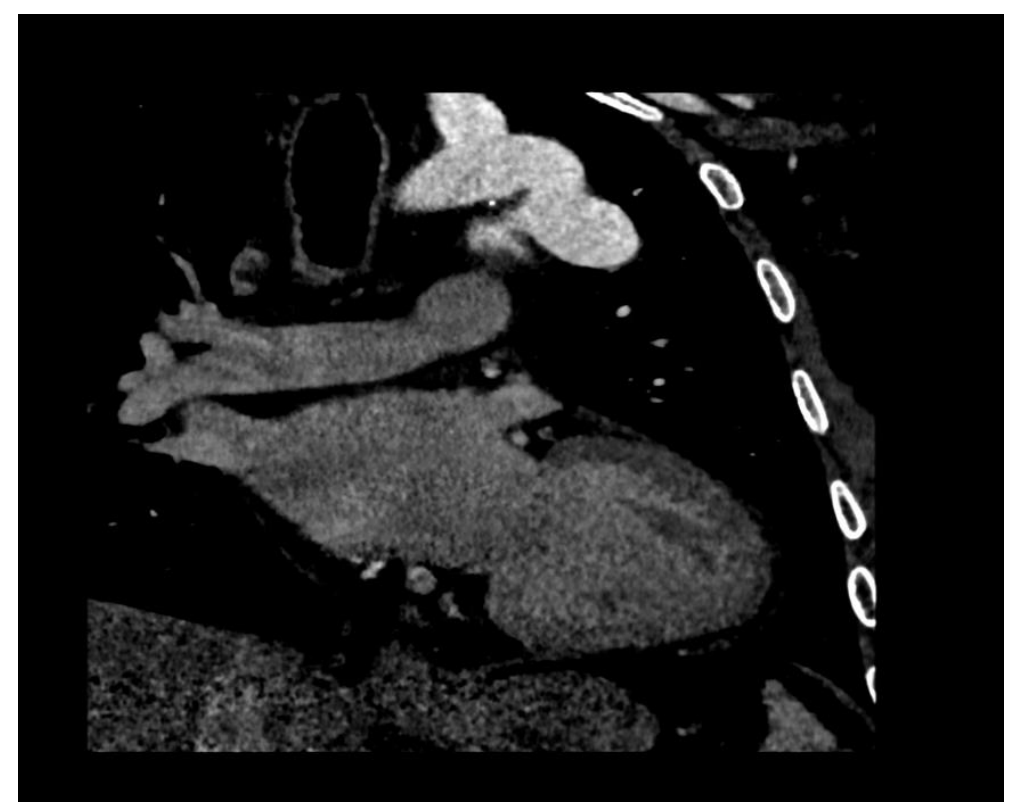

B)

Figure 1: An aneurysmatic dilatation is observed in the distal part of arcus aorta (A: Volume Rendering, B: oblique Multiplanar (MPR) images).

Ferhat Can Piskin, Erol Huseyin Aksungur, Kairgeldy Aikimbaev

Department of Radiology, Balcali Hospital, Medical Faculty

Cukurova University, Adana, Turkey

Peer-review: Internal

Conflict of interest: None to declare

Authorship: F.C.P., E.H.A. and K.A. equally contributed to preparation of quiz Acknowledgement and funding: None to declare

Address for Correspondence: Ferhat Can Piskin, Department of Radiology, Balcali Hospital, Medical Faculty, Cukurova University, Adana, Turkey Email: ferhatcpiskin@gmail.com

Received: 21.08.2019 Accepted: 22.08.2019

Copyright (C) 2019 Heart, Vessels and Transplantation

doi: 10.24969/hvt.2019.142 